\title{
SPECTROSKOPI FOURIER TRANSFORM INFRARED (FTIR) ASAM HUMAT DARI KOMPOS KOTORAN AYAM DENGAN BIODEKOMPOSER BERBEDA
}

\section{Fourier Transform Infrared (FTIR) Spectroscopy of Humic Acid from Chicken Manure Compost with Different Biodecomposers}

\author{
Ratri Noorhidayah1)*, Muhammad Bachtiar Musthafa 2) dan Sisno1) \\ 1) Laboratorium Ilmu Tanah, Fakultas Pertanian, UNSOED, Purwokerto, 53123 \\ 2) Laboratorium Agronomi dan Hortikultura, Fakultas Pertanian, UNSOED, Purwokerto, 53123
}

\begin{abstract}
Humic acid is the final compound resulting from decomposition and humification so that it is more resistant. The role of humic acid includes: reinforcing agents to increase the efficiency of electrokinetic remediation from arsenic contamination, limiting the toxicity of $\mathrm{Cd}$ and $\mathrm{Pb}$ to earthworms in the soil, cementing agents in the soil matrix to suppress environmental degradation of mineral mining. The research was conducted to obtain humic acid extract from compost of agricultural and livestock waste. Humic acid is extracted from compost using strong acids and strong bases. Compost from chicken manure is expected to be a solution for livestock waste that has the potential to pollute the environment. The composting of chicken manure is combined with agricultural waste and weeds such as straw, corncob, banana weevil, durian skin and water hyacinth. Decomposition was carried out with the help of EM4 biodecomposer, Compost Yeast and Earthworms. The functional groups that characterize humic acid from chicken manure compost with a variety of additives and biodecomposers are the absorption peak $3450-3300 \mathrm{~cm}^{-1}, 2980-2920 \mathrm{~cm}^{-1}, 1660-1630 \mathrm{~cm}^{-1}$ and 1170-950 $\mathrm{cm}^{-1}$. The low degree of humification in all treatments is a characteristic of effective compost with the barrel. EM4 is most effective at increasing the rate of decomposition of organic matter in the treatment
\end{abstract}

Key words: FTIR, Humic Acid, chicken manure compost, EM4, worms..

\section{ABSTRAK}

Asam humat merupakan senyawa akhir hasil dekomposisi dan humifikasi sehingga lebih bersifat resisten. Peranan asam humat antara lain : bahan penguat untuk meningkatkan efisiensi remediasi elektrokinetik dari kontaminasi arsenik , membatasi toksisitas $\mathrm{Cd}$ dan $\mathrm{Pb}$ pada cacing tanah di dalam tanah, agen penyemen dalam matriks tanah untuk menekan degradasi lingkungan tambang mineral. Penelitian dilakukan guna mendapatkan ektrak asam humat dari kompos limbah pertanian dan peternakan. Asam humat diekstrak dari kompos dengan menggunakan asam kuat dan basa kuat. Kompos dari Kotoran ayam diharapkan menjadi solusi limbah peternakan yang berpotensi mencemari lingkungan. Pembuatan kompos kotoran ayam dipadukan dengan limbah dan gulma pertanian seperti jerami, bonggol jagung, bonggol pisang, kulit durian dan eceng gondok. Dekomposisi dilakukan dengan bantuan biodekomposer EM4, Ragi Kompos dan Cacing tanah. Gugus fungsional yang menjadi penciri asam humat dari kompos kotoran ayam dengan beragam bahan tambahan dan biodekomposer yakni Puncak serapan 3,450 - 3,300 $\mathrm{cm}^{-}$ $1,2,980-2,920 \mathrm{~cm}^{-1}, 1,660-1,630 \mathrm{~cm}^{-1}$ dan $1,170-950 \mathrm{~cm}^{-1}$. derajat humifikasi yang rendah di semua perlakuan merupakan penciri kompos dengan dengan tong berjalan efektif. EM4 paling efektif untuk meningkatakan laju dekomposisi bahan organik pada perlakuan.

Kata kunci: FTIR, Asam Humat, kompos kotoran ayam, EM4, Cacing.

\section{PENDAHULUAN}

Asam humat merupakan komponen penting dari kompos, humus, gambut, batu, hingga batu bara, dimana merupakan makropolimer asam dengan elektrolit lemah dari gugus karboksilat dan fenolik - $\mathrm{OH}$, dengan berat molekul mencapai 100,000. asam humat bersama dengan asam fulvat dan asam hematomelanin merupakan senyawa akhir hasil dekomposisi dan humifikasi sehingga lebih bersifat resisten. Pada penelitian terbaru, asam humat memiliki peranan antara lain : bahan penguat untuk meningkatkan efisiensi remediasi elektrokinetik dari kontaminasi arsenik (Li et al., 2020), membatasi toksisitas $\mathrm{Cd}$ dan $\mathrm{Pb}$ pada cacing tanah di dalam tanah (Bai et al., 2020), agen penyemen dalam matriks tanah untuk menekan degradasi lingkungan tambang mineral (Miranda et al., 2020).

Produksi asam humat telah dilakukan secara masif di Amerika dan Eropa dengan sasaran konsumen untuk kesehatan manusia, hewan, ternak, lingkungan tanah dan tanaman (Enrich Humic Acid Supplement, Humic-ht, FULHUMIX, dan lainnya), tetapi di Indonesia, produksi asam humat masih terbatas dan masih sebatas digunakan untuk lingkungan pertanian.

Asam humat dapat diekstrak dari kompos dengan menggunakan asam kuat dan basa kuat. Kompos sebagai pupuk organik padatan berasal dari tumbuhan mati, kotoran hewan dan atau bagian hewan dan/atau limbah organik lainnya yang telah melalui proses rekayasa, dapat diperkaya dengan bahan mineral dan/atau mikroba yang bermanfaat untuk meningkatan kandungan hara dan bahan organik 
tanah serta memperbaiki sifat fisik, kimia dan atau biologi tanah (Permentan RI No.1/2019, yang terdiri dari senyawa non-humat dan senyawa humat (Essington, 2003), dimana senyawa humat lazim disebut humus dengan struktur morfologi yang tidak menyerupai asal dan telah mengalami proses humifikasi. Pembuatan kompos pada dasaranya menurunkan rasio $\mathrm{C}$ dan $\mathrm{N}$ dari bahan segarm sehingga proses dekomposisi berhenti. Bahan kompos yang digunakan yakni kotoran ayam boiler dan limbah pertanian/gulma yang ketersediannya melimpah.

Kotoran ayam merupakan limbah peternakan yang berpotensi mencemari lingkungan bila tidak diatasi. Unsur nitrogen dan sulfida yang terkandung dalam kotoran ayam basah berpotensi menjadi gas amonia, gas hidrogem sulfida, dimetil sulfida, karbon sulfida, nitrat, nitrit dan merkaptan bila tertumpuk tanpa pengolahan. Senyawa tersebut dapat tercium dengan mudah walau dalam konsentrasi yang sangat kecil (Rachmawati, 2000). Kandungan unsur hara dalam kotoran ayam adalah sangat tinggi karena bagian cair (urin) tercampur dengan bagian padat (Roidah, 2013). Hasil uji analisis kompos kotoran ayam menunjukkan $\mathrm{pH}=6,8$, C-organik $=12.23 \%, \mathrm{~N}$-total $=1.77 \%, \mathrm{P}_{2} \mathrm{O}_{5}=27.45(\mathrm{mg}$ $100 \mathrm{~g}^{-1}$ ) dan $\mathrm{K}_{2} \mathrm{O}=3.21$ (mg $100 \mathrm{~g}^{-1}$ ) (Tufaila et al., 2014).

Jerami sebagai limbah pertanian mengandung selulosa $32.28 \%$, lignin $4.48 \%$ dengan rasio C/N 105. Saat jerami dikomposkan dengan perlakuan EM4 $30 \mathrm{ml}$ selama 60 hari, didapatkan senyawa humat mulai terbentuk pada hari ke 20 dengan asam fulvat lebih tinggi dibanding asam humat dengan ratio $\mathrm{AH} / \mathrm{AF}$ pada ke-60 sebesar 0,34 pada kompos dengan ratio C/N 37,5(Agustian, 2004). Bonggol jagung merupakan limbah pertanian yang ketersediaannya cukup tinggi dan sukar diolah bila dalam kondisi basah. Kandungan utama bonggol jagung yakni selulosa (41\%) dan hemiselulosa (36\%), sehingga berpotensi dalam penyumbang unsur $\mathrm{C}$ dalam dekomposisi kompos. Eceng gondok sebagai gulma air di waduk maupun sungai, dapat dimanfaatkan sebagai pupuk organik dengan kandungan $\mathrm{N}$ $=1.86 \%, \mathrm{P}=1.2 \%, \mathrm{~K}=0.7 \%$, rasio $\mathrm{C} / \mathrm{N}=6.18$, bahan organik $=25.16 \%$, dan $\mathrm{C}$ organik $=19.61 \%$ (Syawal, 2010). Kulit durian secara proporsional mengandung unsur selulosa yang tinggi (50-60\%) dan kandungan lignin (5\%) serta kandungan pati yang rendah (5\%). (Marlinawati, 2015). Bonggol pisang merupakan limbah pertanian yang banyak tersedia dan jarang dimanfaatkan dan diolah.

Biodekomposer digunakan dalam pengkomposan untuk mempercepat proses dekomposisi dan humifikasi. Mikroorganisme yang terdapat dalam EM4 memberikan pengaruh yang baik terhadap kualitas pupuk organik, sedangkan ketersediaan unsur hara dalam pupuk organik sangat dipengaruhi oleh lamanya waktu yang diperlukan bakteri untuk mendegradasi sampah (Yuwono, 2006). Penambahan volume EM4 meningkatkan kandungan N, P dan C secraa fluktiatif (Nur et al., 2016). Ragi kompos digunakan pula sebagai dekomposer dengan kandungan tertera aktivator nutrisi, hormon pengatur timbuh, probiotic microbes obligat facultatif dalam kondisi dorman: Acetobacter, aspergilus niger, Rhizobium sp, Rhizophus sp. proteolitik, amilolitik, selulolitik, pelarut phosphate, pengikat Nitrogen bebas, trichoderma sp, dan Gliocladium $\mathrm{sp}$.

Vermikompos merupakan metode pengkomposan dengan memanfaatkan cacing sebagai perombak bahan organik dengan memakan semua jenis bahan organik sebanyak berat badannya per hari. Kotoran cacing inilah yang menjadi kompos pada kotak bersekat (Simanungkalit, 2012).

Fourier Transform Infra Red (FTIR) telah digunakan secara luas dimasa lalu untuk pencirian bahanbahan humat, meskipun masih ada keraguan mengenai spektra inframerah karena kerumitan spektra inframerah preparat humat dan kemurnian contoh. Spektroskopi inframerah telah terbukti sangat berguna dan dapat mengidentifikasi tiga tipe fraksi humat yang berbeda, seperti asam fulvat, asam humat dan asam hematomelanat (Tan, 1982). FTIR dapat diterapkan untuk menganalisis kompos, tanah mineral, dan bahan humus, serta perkembangan profil tanah-tanah hutan (Purwanto et al., 2008).

Tujuan dari penelitian ini adalah untuk mengetahui gugus fungsional yang menjadi penciri asam humat dari kompos kotoran ayam dengan beragam bahan tambahan dan biodekomposer. Diduga asam humat dari semua kompos menunjukan serapan kuat terhadap getaran $\mathrm{C}-\mathrm{H}$ pada 2,980-2,920 $\mathrm{cm}^{-1}$, serapan lebih kuat pada getaran karboksil maupun karboknil dalam bentuk COO- masingmasing pada $1,650 \mathrm{~cm}^{-1}$ dan $1,720 \mathrm{~cm}^{-1}$, sebagaimana puncak yang muncul pada asam humat murni (Muzakky, 2003)

Penelitian dilaksanakan di screen house dan laboratorium Tanah Fakultas Pertanian Universitas Jenderal Soedirman, Karangwangkal, Purwokerto Utara dari bulan Februari hingga November 2020.

\section{BAHAN DAN METODE}

Penelitian dilakukan dengan dua tahap, yakni 1) pembuatan kompos dan 2) analisis spektral dan kimia humus dan senyawa humat. Pada tahap 1, bahan yang diperlukan adalah (1) gulma eceng gondok dari Wanadadi, Banjarnegara, (2) jerami padi sisa panen lokal Purwokerto, (3) limbah tonggol jagung (4) limbah bonggol pisang (5) limbah kulit durian (6) kotoran ayam boiler. Bahan organik tersebut dikombinasikan antara tumbuhan/sisa tanaman dengan kotoran, guna menaksimalkan interaksi Karbon dan Nitrogen. Sebagai dekomposer kompos yang digunakan pada penelitian ini adalah (1) cacaing tanah (vermikompos), inokulasi mikroorganisme dengan merek dagang berikut (2) EM4 (3) Ragi Kompos. Perlakuan yang dilakukan didapat $1 \times 5 \times 3=15$ unit kompos.

Kombinasi Perlakuan :

1. A = Kotoran Ayam;

2. $\mathrm{B}=$ Bonggol jagung; $\mathrm{D}=$ Durian; $\mathrm{P}=$ bonggol Pisang; $\mathrm{J}=$ bonggol Jagung; $\mathrm{E}=$ Eceng Gondok

3. $\mathrm{C}=$ Cacing Tanah (Vermikompos); $\mathrm{E}=\mathrm{EM} 4 ; \mathrm{R}=\mathrm{Ragi}$ Kompos.

Pengkomposan dilakukan pada alat komposter aerob berupa tong kapasitas 50 L. Metode yang digunakan dalam pengkomposan adalah (1) vermikompos untuk dekomposer cacing tanah (2) pengkomposan aerob tinggi temperatur dengan mikroorganisme. Alat yang diperlukan dalam penelitian ini meliputi tong pengkomposan, termometer udara, sekop, polybag, kantong plastik, plastik sampel, alat tulis, kertas label. 


\section{Analisis Fisik dan Kimia}

Variabel Fisik dan Kimia yang diamati dalam penelitian ini meliputi suhu pengkomposan, derajat humifikasi kompos, kadar C-Organik kompos, dan rasio $\mathrm{C} / \mathrm{N}$ kompos.

\section{Fraksionasi Asam Humat}

250 gram kompos kering angin ditambahkan dengan 3L larutan $\mathrm{NaOH} 0.1 \mathrm{M}$. digojok selama 2 jam didiamkan semalam. Keesokan harinya, cairan disaring dengan kapas dan filtrate disetrifugasi dg kecepatan 3950 rpm selama 15 menit. Saring filtrat dengan pompa vakum dan kertas whatman 42. Filtrate diasamkan dg HCL pekat, digojok 2 jam didiamkan 24 jam. Disentrifuge 395015 menit. Supernatan yang menggumpal adalah asam humat. Saring supernatan dengan kertas whatman 42. Asam humat didapat dari endapan yang ada dikertas saring. Endapan dicuci empat kali dengan larutan $\mathrm{HCl} 0.1 \mathrm{M}$ : $\mathrm{HF} 0.3 \mathrm{M}=1$ : 1. Pencucian dilakukan dengan wadah plastik. Hasil pencucian kemudian dicuci dengan aquades. Endapan hasil pemurnian kemudian dioven pada suhu $40{ }^{\circ} \mathrm{C}$. Asam humat yang telah murni dikarakterisasi dengan spektrometer FTIR. (IHSS Method, 2013).

\section{Analisis Spektroskopi FTIR}

Pengujian dilakukan sesuai dengan SOP alat Spektrofotometer Spektrum 100 Perkin Elmer Model : Frontier S/N: 96772IR dengan menggunakan pelet K-Br, pada rentang bilangan gelombang $4,000 \mathrm{~cm}^{-1}$ sampai 400 $\mathrm{cm}^{-1}$

\section{HASIL DAN PEMBAHASAN}

Pengkomposan dilakukan selama 12 minggu dengan pengamatan satu minggu sekali untuk mengetahui proses dekomposisi berjalan optimal. Kompos yang sudah matang dipanen berkala untuk kemudian dipindah tempatkan dan di ekstrak.

Suhu selama proses dekomposisi bahan organik di pengaruhi biodekomposer yang diaplikasikan (Gambar 1). Suhu tertinggi proses pengkomposan dicapai hingga $48{ }^{\circ} \mathrm{C}$ pada minggu ke 4 pada perlakuan $\mathrm{ABE}$ (kotoran ayam + Bonggol jagung + Em4), tetapi pada minggu ke 5 dan seterusnya, suhu pengkomposan turun hingga $32{ }^{\circ} \mathrm{C}$. Perlakuan AEE (Eceng gondok) mengalami kenaikan suhu pada minggu ke 4 hingga minggu ke lima $\left(48^{\circ} \mathrm{C}\right)$ kemudian turun memasuki minggu ke 6. Secara keseluruhan, proses kenaikan suhu selama pengkomposan berjalan optimal pada perlakuan EM4 dibandingkan perlakuan ragi kompos dan cacing. Hal ini menunjukan perombakan karbon dan nitrogen berjalan lebih cepat dengan bantuan bakteri dan jamur pendekomposisi, dibanding ragi (jamur) maupun mesoorganisme cacing. Pada perlakuaan dekomposisi dengan sistem vermikompos tidak menaikan suhu secara drastis, berkisar pada suhu $28^{\circ} \mathrm{C}$ hingga $30^{\circ} \mathrm{C}$.

Tabel 1 merupakan hasil analisis karbon dan nitrogen dari bahan segar yang dikomposkan. Seluruh bahan segar menunjukan rasio $\mathrm{C} / \mathrm{N}$ yang tinggi. dekomposisi bertujuan menurnkan rasio $\mathrm{C} / \mathrm{N}$ hingga dibawah 20. Syarat mutu kompos dari sampah organik domestik menurut SNI 19-7030-2004 memiliki rasio C/N 10-20.

Nisbah E4/E6 ditetapkan berdasarkan warna ekstrak kompos di dalam spektro $U V$-VIS pada puncak serapan $400 \mathrm{~nm}$ dan $600 \mathrm{~nm}$. Kisaran nisbah E4/E6 dari semua kompos pada minggu ke 6 dan minggu ke 12 memiliki nilai rerata 3-4, hal ini mengindikasikan adanya asam humat dan senyawa lain yang memilki berat molekul tinggi (Tan, 2008).

Nisbah E4/E6 pada AJC (Ayam-Jerami-Cacing, APC (Ayam-Pisang-Cacing) dan AEE (Ayam-Eceng-Em4) menunjukan nilai dibawah 3. Nilai nisbah E4/E6 yang rendah menunjukan tataran kodensasi senyawa karbon aromatik dan tataran humifikasi bahan humus yang tinggi ,. Diduga Perlakuan vermikompos diduga lebih mengarah pada pembentukan struktur aromatis.

Bahan organik dengan $\mathrm{C} / \mathrm{N}$ rasio lebih dari 60 , mengalami perombakan oleh mikroorganisme tanah (dekomposer) dengan memanfaatkan nitrogen yang ada dalam bahan organik dan nitrogen bebas dari udara sebagai sumber energi kemudian melepaskan energi (panas) dan $\mathrm{CO}_{2}$ ke udara. Setelah lebih kurang 4 sampai 6 minggu bahan makanan dekomposer (C-organik) berkurang, maka terjadi proses mineralisasi dengan melepaskan kembali unsur $\mathrm{N}$ ke dalam tanah. Bahan organik dengan $\mathrm{C} / \mathrm{N}$ ratio kurang dari 40, proses perombakan memerlukan waktu relatif cepat dibanding bahan organik laju dekomposisi pada bonggol pisang berjalan lebih lambat dari bahan segar lain, dilihat dari nilai rasio $\mathrm{C} / \mathrm{N}$ diatas $40 \%$ untuk ketiga perlakuan.

\section{Analisis Spektroskopi FTIR}

FTIR digunakan untuk mengidentifikasi struktur material. Karena setiap tipe ikatan yang berbeda mempunyai sifat frekuensi vibrasi yang berbeda, dan bahkan meskipun tipe ikatan yang sama tetapi dalam dua senyawa yang berbeda (lingkungan yang sedikit berbeda) mempunyai sifat frekuensi vibrasi yang berbeda pula. Maka tidak ada dua molekul yang berbeda strukturnya akan mempunyai bentuk serapan inframerah atau spektrum inframerah yang tepat sama. Dengan melacak atau membandingkan spektral inframerah dari dua senyawa yang diperkirakan identik maka seseorang dapat menyatakan apakah kedua senyawa tersebut identil atau tidak. Jika puncak spectrum inframerah kedua senyawa tepat sama maka dalam banyak hal dua senyawa tersebut adalah identik (Sastrohamidjojo, 1992). Pengelompokan asam humat ektrak kompos kotoran ayam dikelompokan berdasarkan perlakuan bahan segar. Didapat puncak serapan 3,450-3,300 $\mathrm{cm}^{-1}$ yang hampir muncul di semua pada asam humat kotoran ayam ( Gambar 3 ). 


\section{Suhu Dekomposisi}

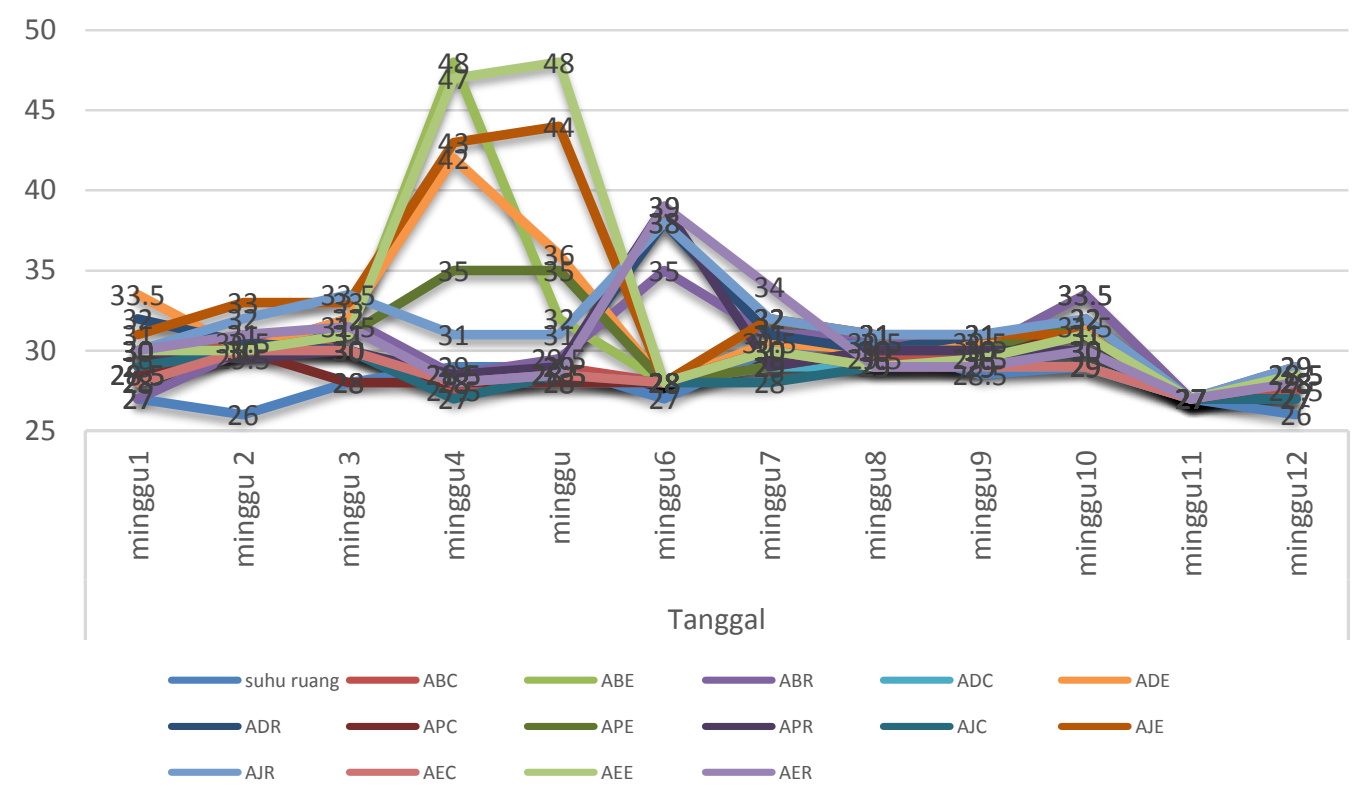

Keterangan : Perlakuan

A $=$ Kotoran Ayam ;

$\mathrm{B}=$ Bonggol jagung $; \mathrm{D}=$ Durian $; \mathrm{P}=$ bonggol Pisang $; \mathrm{J}=$ bonggol Jagung $\mathrm{E}=$ Eceng Gondok

$\mathrm{C}=$ Cacing (Vermikompos) $; \mathrm{E}=\mathrm{EM} 4 ; \mathrm{R}=$ Ragi Kompos.

Gambar 1. Pengamatan suhu dekomposisi kompos

Tabel 1. Kandungan Karbon dan Nitrogen Bahan Segar

\begin{tabular}{ccccc}
\hline No & Bahan segar & C (karbon) \% & N (nitrogen) $\%$ & Rasio C/N \\
\hline 1 & Kot. ayam & 40.9 & 1.5 & 27.26666667 \\
2 & Bonggol jagung & 32.75 & 0.9 & 36.38888889 \\
3 & Eceng gondok & 30.9 & 1.61 & 19.19254658 \\
4 & jerami & 50.9 & 1.82 & 27.96703297 \\
5 & Kulit durian & 56 & 2.21 & 25.33936652 \\
6 & Bonggol pisang & 39.9 & 0.63 & 63.33333333 \\
\hline
\end{tabular}

Tabel 2. Kandungan Karbon dan Nitrogen Bahan Segar

\begin{tabular}{|c|c|c|c|c|c|c|c|}
\hline \multirow{2}{*}{ NO } & \multirow{2}{*}{ Perlakuan } & \multicolumn{2}{|c|}{ derajat humifikasi } & \multirow{2}{*}{ C Organik } & \multirow{2}{*}{ Bahan Organik } & \multirow{2}{*}{$\mathrm{N}$ total } & \multirow{2}{*}{ rasio $\mathrm{C} / \mathrm{N}$} \\
\hline & & minggu ke 6 & minggu ke 12 & & & & \\
\hline 1 & $\mathrm{ABC}$ & 3.57 & 3.67 & 35.11 & 60.54 & 2.98 & 20.31 \\
\hline 2 & $\mathrm{ABE}$ & 3.63 & 3.67 & 30.15 & 51.98 & 2.33 & 22.31 \\
\hline 3 & $\mathrm{ABR}$ & 3.86 & 4.69 & 32.02 & 55.20 & 2.23 & 24.75 \\
\hline 4 & $\mathrm{ADC}$ & 3.68 & 3.46 & 28.77 & 49.60 & 3.40 & 14.59 \\
\hline 5 & $\mathrm{ADE}$ & 3.73 & 3.98 & 23.39 & 40.33 & 2.90 & 13.91 \\
\hline 6 & $\mathrm{ADR}$ & 3.55 & 3.20 & 25.78 & 44.45 & 2.18 & 20.39 \\
\hline 7 & $\mathrm{APC}$ & 2.29 & 2.90 & 43.10 & 74.31 & 1.42 & 52.33 \\
\hline 8 & APE & 3.05 & 3.90 & 40.30 & 69.48 & 1.43 & 48.59 \\
\hline 9 & APR & 3.53 & 3.89 & 41.03 & 70.74 & 1.32 & 53.59 \\
\hline 10 & AJC & 2.52 & 3.93 & 41.35 & 71.29 & 2.76 & 25.83 \\
\hline 11 & AJE & 3.70 & 4.60 & 34.21 & 58.98 & 2.12 & 27.82 \\
\hline 12 & AJR & 3.66 & 3.70 & 39.26 & 67.69 & 2.15 & 31.48 \\
\hline 13 & $\mathrm{AEC}$ & 3.50 & 3.90 & 43.05 & 74.22 & 3.20 & 23.20 \\
\hline 14 & AEE & 2.64 & 4.23 & 41.21 & 71.05 & 2.98 & 23.84 \\
\hline 15 & AER & 3.52 & 3.89 & 40.67 & 70.12 & 2.95 & 23.77 \\
\hline
\end{tabular}




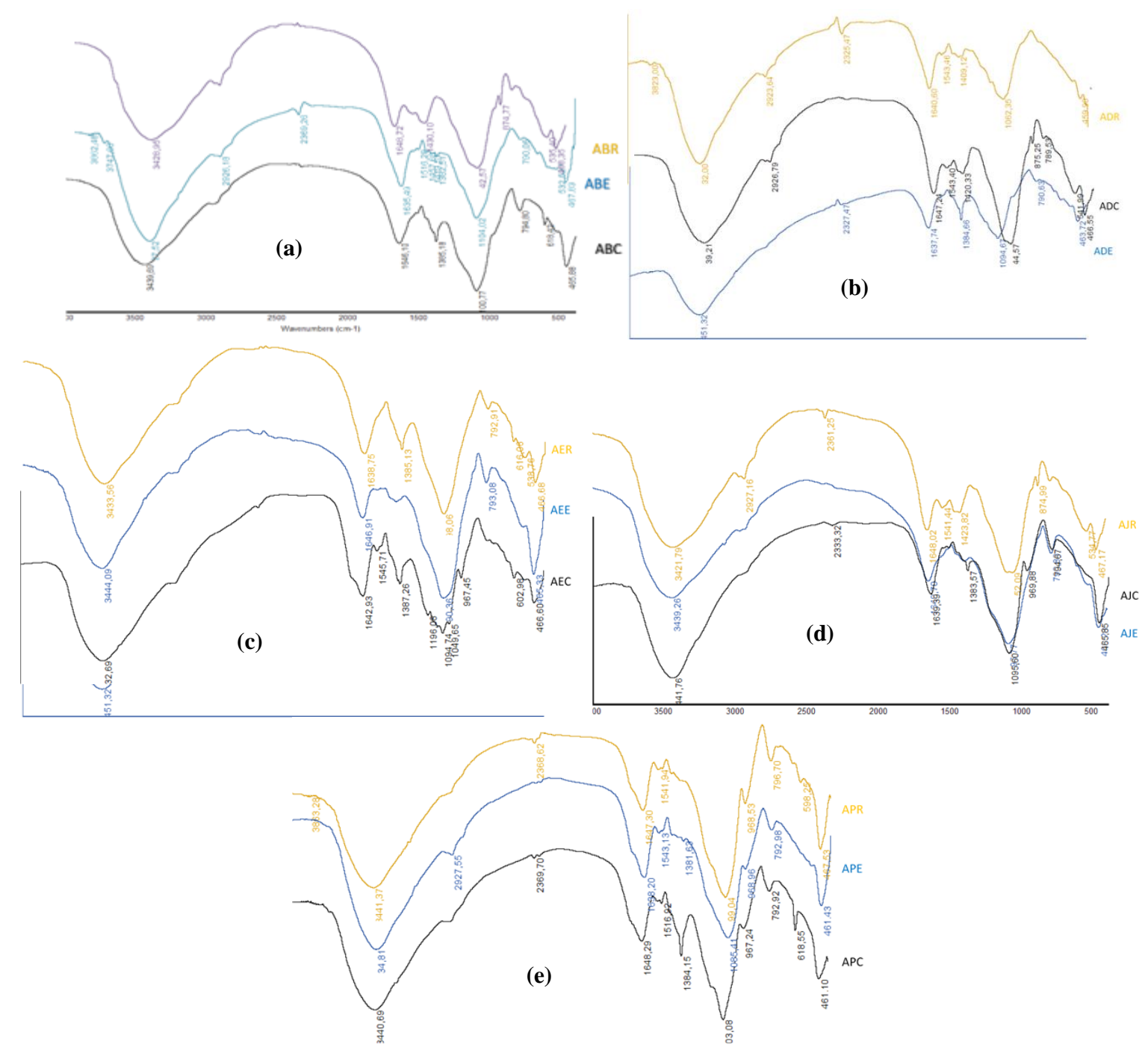

Gambar 3. Puncak Serapan Asam Humat: (a) Kotoran Ayam +Bonggol Jagung, (b) Kotoran Ayam +Durian, (c) Kotoran Ayam +Eceng Gondok, (d) Kotoran Ayam +Jerami, dan (e) Kotoran Ayam +Bonggol Pisang,

Puncak serapan 3,450-3,300 $\mathrm{cm}^{-1}$ yang muncul disemua perlakuan merupakan indikasi ikatan hidrogen grup $\mathrm{OH}, \mathrm{OH}$ bebas, ikatan intermolekular $\mathrm{OH}$, vibrasi ulur $\square(\mathrm{O}-\mathrm{H})$ dan atau vibrasi ulur $\mathrm{N}-\mathrm{H}$ muncul disemua asam humat kompos, dengan nilai tertinggi AEE 3,444.009 $\mathrm{cm}^{-1}$ \& luas area $40.526 \%$. Pergeseran dan melebarnya puncak vibrasi ulur $-\mathrm{OH}$ tersebut diduga sebagai akibat dari makin kompleksnya tipe ikatan hydrogen yang ada pada senyawa asam humat (Baes dan Bloom,1989).

Puncak serapan kedua yang muncul di semua perlakuan yakni puncak $2980-2920 \mathrm{~cm}^{-1}$, sebagai indikasi getaran $\mathrm{C}-\mathrm{H}$ serapan lebih kuat pada getaran karboksil maupun karboknil. Puncak serapan ketiga yang muncul di semua perlakuan yakni puncak $1,660-1,630 \mathrm{~cm}^{-1}$ sebagai penanda adanya Vibrasi ulur $\mathrm{c}=\mathrm{o}$ dari grup amida (amida 1), kuinon $\mathrm{C}=\mathrm{O}$ dan/atau $\mathrm{C}=\mathrm{O}$ dari ikatan $\mathrm{H}$. Pada $\mathrm{ABR}$, peak bergeser pada $1,648.72 \mathrm{~cm}^{-1}$, diduga sebagai Vibrasi ulur $\mathrm{C}=\mathrm{O}$ dari asam karboksilat, siklik dan asiklik aldehid dan keton, kuinon 900-690 $\mathrm{cm}^{-1}$ sebagai penanda adanya C$\mathrm{H}$ dari cincin aromatik menunjukan ciri asam humat memiliki senyawa aromatik.

Puncak serapan keempat yang muncul di semua perlakuan 1,170-950 $\mathrm{cm}^{-1}$ merupakan penciri vibrasi ulur $\mathrm{C}-\mathrm{O}$ dari polisakarida atau mirip substansi polisakarida, $\mathrm{Si}-$ $\mathrm{O}$ dari silikat. Polisakarida merupakan molekul karbohidrat polimerik yang tersusun atas rantai monosakarida yang panjang dan terikat oleh ikatan glikosidik. bentuk jamak pada sel tumbuhan dan hewan

Puncak yang muncul disemua perlakuan diindikasikan sebagai penciri asam humat karena puncak tersebut yang muncul pada asam humat murni (Muzakky, 2003)

Pengelompokan gambar puncak serapan asam humat ektrak kompos kotoran ayam dikelompokan berdasarkan perlakuan bahan segar, yang hasilnya menunjukan pengaruh bahan segar memberikan lebar dan kedalamn puncak serapan yang hampir seragam untuk masing-masing perlakuan bahan segar. Hal ini mengindikasikan perbedaan bentuk asam humat dipengaruhi bahan pembentuknya.

\section{SIMPULAN}

Gugus fungsional yang menjadi penciri asam humat dari kompos kotoran ayam dengan beragam bahan tambahan dan biodekomposer yakni Puncak serapan 3,450 - 3,300 $\mathrm{cm}^{-1}, 2,980-2,920 \mathrm{~cm}^{-1}, 1,660-1,630 \mathrm{~cm}^{-1}$ dan $1,170-950 \mathrm{~cm}^{-1}$.

Asam humat merupakan senyawa ektraksi humus kompos dan kompleks. Komposisi asam humat yang 
terindikasi di 15 jenis kompos yakni : $\mathrm{C}=\mathrm{C}$ aromatik, $\mathrm{H}$ berikatan kuat dengan $\mathrm{C}=\mathrm{O}$ dari konjugasi keton, Getaran vibrasi ulur $\mathrm{C}-\mathrm{C}$ dari ikatan ganda pada komponen siklik dan asiklik, cincin benzena, subtitusi (Lignin dan aromatik lain, atau karboksilat aromatik dan alifatik), polisakarida.

Pengkomposan model tong aerob terbukti efektif untuk kompos campuran limbah pertanian dengan feses ternak, dibuktkikan dengan nilai derajat humifikasi yang rendah di semua perlakuan

Pengkomposan dengan EM4 paling efektif untuk meningkatakan laju dekomposisi bahan organik

\section{UCAPAN TERIMA KASIH}

Ucapan terima kasih disampaikan kepada LPPM Universitas Jenderal Soedirman yang telah membiayai penelitian skim dosen pemula ini, sehingga penelitian dapat berjalan dengan lancar.

\section{DAFTAR PUSTAKA}

Bai, H., M. Luo, S. Wei, Z. Jiang dan M. He. 2020. The vital function of humic acid with different molecular weight in controlling $\mathrm{Cd}$ and $\mathrm{Pb}$ bioavailability and toxicity to earthworm (Eisenia fetida) in soil. 2. Journal of Cleaner Production, 279.

Kononova, M.M. 1975. Soil Organik Matter. Pergamon, London.
Li, J., Y. Ding, K. Wang, N. Li, G. Qian, Y. Xu dan J. Zhang. 2020. Comparison of humic and fulvic acid on remediation of arsenic contaminated soil by electrokinetic technology. Chemosphere, 241(February 2020): 125038.

Marlinawati, B. Yusuf dan Alimuddin. 2015. Pemanfaatan Arang Aktif Dari Kulit Durian (Durio Zibethinus L.) Sebagai Adsorben Ion Logam Kadmium (II). Jurnal Kimia Mulawarman, 13(2015). P-ISSN 1693-5616

Mirandaa, G.A. Portillo., et al. 2020. Humic substances reduce the erodibility of soils in mining areas. Journal of Cleaner Production, 279(2021): 123700.

Purwanto, 1992. Laksana Humus dan Kompleks Al-/FeAndosol di Sepanjang Lereng Utara Gunung Slamet pada Beberapa Ketinggian Tempat. Tesis. Fakultas Pertanian UGM, Yogyakarta.

Purwanto, B., et al. 2008. Kinetika Mineralisasi Nitrogen Untuk Mengestimasi Ketersediaan Nitrogen Pada Tanah-Tanah Gambut. Laporan Penelitian. UGM. Yogyakarta

Rachmawati, S. 2020. Upaya Pengelolaan Lingkungan Usaha Peternakan Ayam. Wartazoa, 9(2).

Yuwono, T. 2006, Kecepatan Dekomposisi dan kualitas Kompos Sampah Organik. Jurnal Inovasi Pertanian, 4(2). 